\title{
1. Presentation and premises
}

I think with them. That, no doubt, is friendship.

(Nicolas Bourriaud, 2002, p. 5)

\section{HOW THE IDEA FOR THE BOOK CAME ABOUT}

The idea for this book emerged over the course of a year (or more). Whenever we met for coffee or wine, our talk would - immediately or eventually - come around to work; not just what we were working on, but also how we were working. It became clear that we both had an interest in how academic work is carried out in practice and more specifically in the many different work practices and processes that are necessary to accomplish what one wants to realize.

In our experience, many of the practices and processes that constitute academic work are not part of the knowledge that is passed on from seniors to juniors or even talked about in the academic workplace at all. Thus, homemade practices abound; some practices are useful, others less so. Therefore, we had a need for joint reflection on how we work, in order to inspire each other to do things differently and better, or just to feel good about what we were already doing. We believe that other researchers have the same need. The idea for this book is therefore to create a space for the reader to reflect with us and the book's contributors in order to become inspired and feel good about all the ways in which academic work, and more specifically theorizing, can be carried out in practice.

It is easy to explain why we have this common interest in practice. Anne has a background in anthropology and as such she is interested in understanding what people do and how they ascribe meaning to their practice. Sabine has a background in organizational studies and her research centres on understanding how work gets done in organizations, using theory as a tool for uncovering practices that 
are important for the work, but which may somehow fly under the radar of articulation. Because of our backgrounds and research interests, we see theories as useful analytical lenses and guidelines with which to understand and act in practice. But the main interest in this context is to explore theorizing as a particular type of academic work that involves different work practices and more or less messy processes. But which practices and processes? And more specifically, which practices and processes are key to developing interesting and relevant theories that are picked up by the community?

While there are many books and papers that focus on research methods, far fewer resources address theory development as their primary objective. Existing sources typically look at what theory is and what the building blocks of theory ought to be, as well as which steps to take during the theory development process (see, e.g., James Jaccard and Jacob Jacoby, 2009; Richard Swedberg, 2014b; David Whetten, 1989b). And they typically do so by drawing on and synthesizing the author's own experiences as a theorist or editor. In this book we use another approach. Instead of delineating our own experiences and thoughts on how theories are or should be developed, we decided to ask recognized organizational researchers if they were interested in participating in an in-depth interview structured around the following overall question: 'What do you do when you engage in theorizing?' To our great and humble surprise, the contributors to this book replied immediately that they were very interested in talking to us. At this point, the idea took shape and changed from an interesting conversational topic to the more daunting task of writing a book based on the themes and findings that could be gleaned from the interviews.

\section{THE PURPOSE OF THE BOOK: INSPIRATION}

Already before we conducted the interviews, the main idea for the book was in place. We wanted to write a book that could inspire the reader to reflect on and develop his or her own practice towards academic theorizing by presenting the breadth and depth of the various both common and different ways of working that recognized organizational researchers use when they engage in thinking processes. 
Rather than a normative step-wise approach to what one should do, we had the metaphors of a mirror room and an echo chamber in mind. The metaphors suggest that some practices will stand out and resonate with some readers and not with others - others who will instead see themselves reflected in other ways of working. Thus, the purpose of the book is to provide a foundation from which the reader can pick and choose among the points and practices that are meaningful to them, while discarding the aspects that are not. In that sense, the book prioritizes thematically structured descriptions of actual practice rather than step-wise prescriptions. If the book contains a normative element, it is by making the claim that it is inspiring to deliberately reflect on, discover and actively choose to use a few key practices, among others, that one believes can make a real difference for the way one theorizes.

\section{GETTING READY FOR THEORIZING}

When we were conducting the interviews, we realized that the interviewees related numerous points, processes and practices that were important for getting ready for theorizing, but the actual theorizing remained somewhat elusive, even when we directly prompted them to speak about what they do when they theorize. Thus, it seems that the actual doing, or the core of what one does, is very difficult to communicate to others.

Moreover, it seems that theorizing is a much more creative endeavour than systematic, step-by-step approaches are able to elucidate. And because of this, what happens when the researcher theorizes remains somewhat mysterious. However, what is clear is that there are ways of getting in the mood for the creative act of theorizing, making this book about the practices and processes that pave the way for theorizing to happen. Moreover, it is an attempt to shed as much light on the unarticulated aspects of theorizing as possible, through interpretations of the interview data. Hopefully, the book will provide insight into the act of theorizing, that is, into what happens in the space between reaching for a thought and expressing the thought: 'Thinking is pleasurable ... [and] it is the slow, organically growing process of thought involved in writing that lets the ideas emerge in the first place' (Mihaly Csikszentmihalyi, 1991, pp. 126, 131). 


\section{THEORY AND THEORIZING}

Theory can be seen as the endpoint of theorizing, typically embodied in a text, while theorizing refers to the process that precedes the final text. As Richard Swedberg (2012) states, the two are inherently connected, but currently the emphasis in academia is on the text (and the publication thereof), which in turn means that little is known about the process of theorizing. In this book, we emphasize theorizing rather than theory. We will, of course, mention which theories the interviewees have developed and highlight the several forms that theory, according to the interviewees, can take - from concepts and metaphors to paradigms. However, the purpose is not to present each of the contributors' work, as we primarily are interested in how they work. So far, we have used the terms theory development and theorizing synonymously and we will continue to do so, among other things, for the pragmatic purpose of creating some linguistic variation. However, we favour the term theorizing, because it refers to a process that is happening; in other words, to theory in the making.

\section{THEORIZING AS A LONG-TERM COMMUNAL PROCESS}

After we had conducted the interviews, it became clear that the traditional notion of seeing theorizing as a process that culminates with (the publication of) theory as text is somewhat misleading. All the interviewees pointed out, in line with literary theory, that a text only exists if it is read, and, as such, if a theory is relevant for the community and for as long as it is relevant (or when it becomes relevant again), theorizing continues to happen. Thus, this book takes a long-term perspective at theorizing and we highlight that the text is not the endpoint of the theorizing process and that the original author(s) is not the only creator. On the contrary, in order for a theory to be successful, so to speak, it has to be picked up by the community and further developed through communal efforts. Thus, theorizing takes time and people. 


\section{THE CHOICE OF INTERVIEWEES}

This book is our attempt at theorizing about how organizational researchers develop theory in practice. To help us shed light on that we needed people. We therefore quickly settled on the in-depth individual interview as a suitable method for inquiring into the topic. Thus, as the idea was to interview key thinkers that are well known and widely used by students and researchers in organization studies, we approached a number of people we were fascinated by and who are considered the giants of the field. Most of these replied immediately that they were interested in participating in the project; a few answered that they had retired or no longer gave interviews; and only a few we never heard back from. As such, there is, of course, a selective and pragmatic aspect to the choice of contributors, in the sense that they reflect who we consider key thinkers and those who were interested in participating in the project.

\section{WHAT THE INTERVIEWEES HAVE IN COMMON}

The contributors to the book replied that they were interested in participating in an interview because they thought that the book addressed other and novel aspects of theorizing compared to that found in the existing literature on the topic. Their motivation for participating made us realize that even though there is much variety in the contributors' choice of research topics and ways of theorizing - from Kenneth Gergen's focus on generative metaphors to Andrew Van de Ven's emphasis on logical arguments - there are also a number of common denominators.

In general, all contributors have an interest in process. This includes a focus on the processes of the phenomena they are researching, but also, importantly for our purposes, the processes whereby theories are (co-)created. As such, the contributors have in common that they are well versed in the existing literature about theory development and philosophy of science; they are interested in what theory is and what theory can be used for as well as in the process of theorizing; and many of them have contributed journal papers, book chapters, and books on these topics. In addition, the interviewees all refer to curiosity as a personal trait. Many people might describe themselves 
as curious because it is considered a valuable thing to be. However, curiosity in this case refers to a need for actively seeking out understanding. This means that if there is something the interviewees find interesting, unexpected or novel they turn to the literature and/or go into the field to come to understand. In other words, it is a type of curiosity that leads to explorative action and a search for meaning.

\section{WHO THE INTERVIEWEES ARE}

We provide two different types of insight into who the interviewees are, as people and as researchers. In Box 1.1, we present an overview of the eight interviews that were conducted for this book. We describe who we interviewed, how, and what their main research interests are and we provide a quote that captures the essence of each contributor's way of thinking about theorizing. The quotes also serve to highlight some of the themes that are addressed in the book.

In addition to this overview, we present a more personal narrative of each contributor in order to provide insight into the link between the person's background and life story, choice of research topics, and ways of working. The personal narratives can be found in boxes at the end of the chapters, where we present either one or two contributors at a time (see the list of boxes at the beginning of the book to locate the narrative description of each of the contributors).

\section{REFLECTIONS ON GENDER}

As mentioned, we have chosen the interviewees based on whom our students, our colleagues, and we are interested in and use in our work. This resulted in more male than female contributors. We found this interesting, because even though we are not gender researchers we are aware of the importance of paying attention to who is talking and who is not; what is being told and what is not; and why this is being told and not something else. In other words, to the classic questions of gender research.

We therefore asked almost all interviewees in a closing remark what it might mean that most of the theories in use in organizational studies 


\section{BOX 1.1 OVERVIEW OF THE INTERVIEWEES}

\section{Professor David Boje}

The interview with David Boje was conducted as a Skype interview from his office at New Mexico State University in Las Cruces, Mexico. David Boje's theorizing focuses on sensemaking, the storytelling organization, and critical inquiry into organizations' use of power. He invented the term 'antenarrative', which refers to a story before it becomes a retrospectively created meaningful whole, that is, before a coherent narrative. And you know what, I was teacher of the year for the whole university in my first semester. It was all about the storytelling. This changed the way ... I just decided: I am only going to write about storytelling, I am only going to teach storytelling, I am only going to do storytelling.'

\section{Professor Barbara Czarniawska}

We conducted the interview with Barbara Czarniawska in person in her office at the University of Gothenburg, Sweden. Barbara Czarniawska's theorizing focuses on processes of organizing, organizational change, fashion and fads in management theories and practice, as well as narratology as a field study technique and analytical lens in organization studies. 'Umberto Eco said many times, metaphors are what we don't know and this is the only thing that is interesting. Facts and names are boring. Metaphors are exactly bisociations, they are putting things together from two different fields. But then, some work and some don't work.'

\section{Professor Kenneth Gergen}

The interview with Kenneth Gergen was conducted as a Skype interview from his home in Pennsylvania, United States. Kenneth Gergen's work focuses on social constructionism and the generative aspects of theory and metaphors. He has invented the terms relational being, saturated self and positive ageing, to name a few. 'Once you are a constructionist, you realize that whatever your theory is, your language is going to create that in its terms. It makes the world what it is ... You ask a totally different set of questions. You ask "How do I want to create the world and what are the implications of creating it in that way?"'

\section{Professor Tor Hernes}

The interview with Tor Hernes was conducted in person in his office at the Copenhagen School of Business, Denmark. Tor Hernes theorizes about organization, time, change and continuity. His work is centred on an eventbased understanding of time, inspired by Alfred North Whitehead's philosophy. 'The way I use others [theorists] from outside the organization field, I use 
them to inspire me, and I sense that I go just to the right depth, so I can say something novel back into my own field, organization studies.'

\section{Professor Emeritus Geert Hofstede}

The interview with Geert Hofstede was conducted as a Skype interview from his home in the Netherlands. Geert Hofstede has researched a number of topics, such as how budgets and financial pressures influence people and organizations. However, he is primarily known for his theory about national cultural differences and the dimensions along which the differences can be understood. 'If you ask me what has been the driving force in my work, it was curiosity. It was whenever I came across something that surprised me, to try to find out; how come? ... [and also] in the practical use of my work ... having an impact.'

\section{Professor Emeritus Edgar Schein}

The interview with Edgar Schein was conducted as a Skype interview from his home in Palo Alto, United States. Edgar Schein has researched a variety of themes during his career, including indoctrination of prisoners of war, indoctrination in organizations (resulting in the discovery of the concept of career anchors), and organizational culture. Moreover, he has written books about process consultation, humble inquiry, and how to be helpful in practice. '[B]uilding on previous theory is not as important as discovering something that is useful [in practice]. How do we discover something useful? ... the starting point should be experience ... you start with good observations, fieldwork, and interviews, and draw theory out of that.'

\section{Professor Emeritus Andrew Van de Ven}

The interview with Andrew Van de Ven was conducted as a Skype interview from his home in Minnesota, United States. Over the course of his academic career, Andrew Van de Ven has worked with group decision-making techniques, organizational assessment methods, organizational change, and innovation processes. Moreover, he has formulated his insights into how to research these themes as a particular research approach labelled 'engaged scholarship' 'To me to be engaged is not to go alone. Do not do your research, do not do your writing alone, do not do anything alone. Especially when we are addressing problems and questions which are bigger than ourselves.'

\section{Professor Emeritus Karl Weick}

The interview with Karl Weick was conducted as a written dialogue. The text is included in this book in full. Karl Weick is one of the founding fathers of the process view in organizational studies, as he early on suggested a shift in perspective from organization to organizing. He is most famous for his writings about sensemaking, which he has studied both with regard to everyday 
affairs, during disasters and in different types of organizations. 'From the beginning I "played the percentages", figuring that, if I keep writing I can write my way into occasional insights. Long before I heard the phrase, my style was to see what I wrote in order to learn what I thought.'

have been developed by men. In response to this question, Barbara Czarniawska read the following text from one of her book chapters aloud for us:

In his book On the Shoulders of Giants, Robert Merton (1965/1985), declared that ... in historical reality it is the appointed giants who stand on a pyramid of midgets. But it is a demand of the narrative convention that big discoveries must be made by big heroes; a story about ant-like workers would be dull ... I would like to suggest yet another possibility: that of a midget, like myself, who ... suddenly discovers that she was, in fact, all the time standing on somebody's shoulders. Was the reason for invisibility that the shoulders belonged to a female person? (Barbara Czarniawska, 2011, p. 217)

The last line is especially striking as it suggests that female thinkers might play a larger role than we realize, due to taken-for-granted notions that academic heroes are men or simply because their influence goes unacknowledged by both men and women. The other interviewees made similar remarks. Moreover, the shared understanding was that there are a lot more women in academia now, but it takes a long time before a theory starts to have a widespread impact and therefore it might still be a few years before their theories become well known and widely used.

If gender plays as large a role as gender theory and research suggests, it might be relevant to point out that we are female thinkers and that the insights presented in this book have been created in response to the questions we have asked and based on our interpretations of the provided answers. For this reason, we also believe that it is important that we present our personal narratives in order for the reader to understand our background and how it influences our way of thinking (see Box 1.2). 


\section{BOX 1.2 OUR PERSONAL NARRATIVES}

\section{Anne Vorre Hansen}

Anne has always had a double side to her: an extrovert and social side and a very quiet introvert one lived out in 'literature escapism. Since her early childhood she has been reading everything from comic albums/strips such as Yoko Tsuno, Prince Valiant and Tintin to philosophy, crime novels and fiction. The two sides are bridged by a profound curiosity towards stories, be they in literature or in dialogue - based on an urge to explore how stories shape experiences, understandings and future actions. The double-sidedness is also mirrored in Anne's work life, as both a consultant and a researcher with an explicit focus on merging the perceptions of users/citizens/customers with the logic of organizations in innovation processes. The word that best captures her approach and motivation is to 'understand,' and especially to understand something better. To Anne this book is therefore motivated by a wish to broaden her horizon and grasp thinking processes more profoundly.

\section{Sabine Madsen}

Sabine grew up in a town in Jutland, Denmark, which happened to have a beautiful and well-stocked library. There she discovered the pleasure of being surrounded by words, stories and ideas at an early age, and later the choice of an academic career was not difficult as it allows for the continual recreation of this childhood experience of immersion in words. As a person, Sabine is interested in the many forms in which words can be used to express thought, such as poetry, fiction, non-fiction as well as in literary theory. As a researcher, this translates into an interest in being a part of - and the understanding and creation of - the flow of ideas in circulation in practice, and more specifically in organizations and organizational studies. The word that best captures both her personal and research interest is 'emergence' the process whereby things such as work practices, theories, works of art and so on come to take the form they do. Thus, writing this book falls directly into the category of a passion project.

\section{REFERENCING PEOPLE}

In this book we draw extensively on the interview statements made by the contributors as well as on other authors and theorists, both from the field of organizational studies and beyond. In all cases, we refer to them as people, that is, with their full name. In line with the abovementioned considerations, we have chosen this referencing style to 
make the gender of the contributors and authors explicit. Moreover, we do it to remind others and ourselves that it is real people - with real desks, computers, coffee cups, assumptions, interests, likes and dislikes - who develop theories. Thus, before someone is a giant, invested with collective meaning and legitimacy that makes him or her larger than human, or a midget, an ant-like worker on the academic treadmill, they are first and foremost a person. To read their theory (or their interview statements) is therefore to get a glimpse into that particular person's thinking. Or, as Siri Hustvedt (2016) would say: 'to read is to engage with a trace of someone else's consciousness through a text, which is impregnated with the author's being'.

\section{READING STYLES AND STRATEGIES}

This book can be read in different ways and for different inspirational purposes. First of all, it can, of course, be read chronologically from one end to the other. We think of this as a reading strategy that can be coined the long gaze. With this strategy, reading takes place over time to grasp the line of thought that is presented in the book as a whole. The term 'the long gaze' also refers to one of the main points of this book, namely that theorizing is more like a marathon than a sprint.

Second, the book can be read one chapter at a time, when the need for inspiration, in general or on a particular topic, arises. We think of this as the short gaze, where reading takes place in one sitting - for example, during a commute, to warm up for the day's work, to pass the time in a hopefully pleasant way, and so on. To cater to this type of reading strategy, each chapter addresses one overall theme and has an introduction, a middle and an end to ensure a complete reading experience.

Third, the book can be read one text chunk or quote at a time. We think of this as sampling for sound bites. With this strategy, reading takes place to become inspired here and now - for example, by opening the book at a random page when in need of fast food for thought, a variation or new tone to one's own writing, or simply a quick distraction. As Kenneth Gergen states: 'I can also get inspired by just reading something. It does not take very much. It depends on the text, but sometimes you can find something pretty quick.' To cater to this type of reading, the content and layout of the book 
has been designed with many quotes, boxes, informative headlines, as well as with a reader-friendly type and spacing. This might sound trivial but we believe that far more people read books using the sampling strategy than we might normally assume. Yet, most books, and particularly academic books, do not take this into account because content is prioritized over presentation. In this book, we have striven to give equal prioritization to content and layout to support different reading styles, which in turn allows the reader to take away different types of inspiration.

\section{STRUCTURE AND CONTENT OF THE BOOK}

The book consists of seven chapters: this introductory chapter, a summary chapter, four content chapters and a 'behind the scenes' chapter, which presents the full interview with Karl Weick. All content chapters follow the same structure. We start each content chapter by introducing the chapter's overall theme and by linking the theme to theoretical concepts of relevance for the subsequent presentation of the empirical findings. The theoretical concepts that set the scene in each chapter have been chosen because they are meaningful to us and because they proved to be useful interpretive devices during our analysis and shared discussions of the interview findings. Thus, we do not provide a comprehensive review of the existing literature or of all the concepts that could be relevant for theorizing in general and for the presented empirical findings. Instead, we use theoretical concepts and references to give the reader a scaffold for understanding the interview findings and to highlight differences and similarities between existing knowledge and our findings.

In addition to theoretical concepts, we use boxes of text as a structural device that allows us to both emphasize key findings from the interviews and challenge established academic notions and expectations, thereby adding extra meaning to the text. Thus, we use boxes in (at least) four different ways:

- to present the personal narratives of the contributors;

- to provide more detail on some of the theoretical concepts and work practices that the contributors point out as particularly important for theorizing; 
- to present longer quotes from the interview material, where the contributors tell a story, give examples of how they work or delineate their line of reasoning;

- to describe anecdotes from the interview situations and from our own experiences as researchers, teachers and supervisors.

After mentioning these structural aspects, we now provide an overview description of the content of the remainder of the book. The logic of the chapters' sequence is that we start in Chapter 2 by exploring how the contributors engage in theorizing and how the groundwork for thinking is conditioned by personal inspiration and practices. Subsequently, in Chapter 3, we dig further into the unit of analysis, trying to expose what it means to look at something and what this looking is motivated by. Then, in the 'intermezzo' chapter 'Behind the Scenes - Interviewing Karl Weick', we explore one of the particularly salient theorizing practices, namely writing. To this end, we present the written interview with Karl Weick in full. This chapter will be the foundation for Chapter 4, where we turn towards the literature base and academic antecedents, recognizing that knowledge production is deeply anchored in history and social processes. In Chapter 5, we zoom out and focus on perceptions of what it means to make a theoretical contribution. Last, in the final chapter, Chapter 6, we sum up key points and practices across interviews and chapter discussions - before leaving the reader to do his or her own thinking and theorizing.

\section{WHAT THE BOOK HAS TO OFFER}

With this book we have written the book we wanted to read, but also the book that we wanted to write. Thus, the book provides:

- insights from interviews with key thinkers in the field of organization studies (what they are doing and what works for them, rather than what one should be doing);

- a focus on aspects that make theorizing a much more personal and meaningful endeavour than just getting published;

- descriptions of different types of work practices and understandings of what the work entails, from Karl Weick's very concrete everyday descriptions of how he starts his writing day 
to Kenneth Gergen's outline of how his academic goals and approaches to theorizing have changed over the course of his career.

We hope that the book can inspire the reader to engage in theorizing, not only as an instrumental work task but also as an existential urge to understand and create new meaning, especially since all contributors have been able to balance between being a human and a professor, as explicated in the poem by James March at the beginning of this book. It might be that 'research is not for sissies', but it certainly seems to be for creative collaborative people with a well-developed sense of humour.

Box 1.3 presents the research approach that we have used to collect and analyse the empirical interview data, which constitutes the foundation for this book.

\section{BOX 1.3 THE RESEARCH APPROACH}

This book is primarily based on data from eight in-depth interviews. The interviews were structured around an interview question guide (see the Appendix to this book) that we sent to the interviewees beforehand. This was done for two reasons. First, it would allow the interviewees to prepare for the interview if they wished to. All interviewees did. Second, it would help with potential language barriers during the interview as they also had the questions in writing.

The interviews were conducted in person, via Skype, or as written dialogue. The oral interviews lasted approximately an hour and a half. They were sound-recorded and subsequently transcribed verbatim. All interviews were conducted in the period from mid-August 2017 to mid-September 2017.

After the interviews had been transcribed verbatim, we made what we would refer to as 'analytical transcripts'. The aim was to make the interviews as reader friendly as possible, by presenting the text according to the themes that the interviewee talked about, deleting repetitions that did not add to the meaning, making conjunctions in places to ensure more fully formed sentences, and by presenting the text in a readable, clear font. Making the analytical transcripts was therefore a first very preliminary round of analysis. Moreover, it was meant as a gift to the interviewees, providing them with a reader-friendly text that presented the meaning they created during the interview. 
The analytical transcripts were sent to the interviewees for approval. All interviewees took time to go through the transcripts, fix mistakes we had made, and to polish the text to convey the meaning of their thinking better. This meant that the transcripts lost some of their spoken quality, and instead became very well-written accounts of the interviewees' thinking about theorizing. This book is based on these corrected and approved transcripts that have been generated through several phases of dialogue, listening, analysis, writing and rewriting. We considered this process important in order to create and collate data for the book as well as possible.

After the data had been created we read through the interview transcripts, identified the main themes, and outlined the structure of the book based on these themes. This can be considered a compositional analysis. Next, we carried out a more detailed analysis of what the content of each chapter should be and this was written down as themes and keywords that captured what we wanted to cover in the particular chapter. After this, another round of analysis was conducted during the writing process. When we started writing one of the content chapters we began with reading the transcripts from the perspective of the overall theme and theoretical concepts of the chapter. Based on this, key findings and selected quotes were included in the already existing detailed outline of the chapter structure - in some cases, resulting in a reworking of the initially delineated chapter themes and sub-themes. Last, the actual writing took place, with one of us as the main author of the first draft. The draft was then revised by both of us until we were satisfied that we had managed to express what we wanted to. 


\section{BOX A BARBARA CZARNIAWSKA - THE PERSONAL NARRATIVE}

Barbara was born in 1948 in Poland into a family of graphomaniacs; her three brothers and herself have all published books. The need to write is also reflected in Barbara's early desire to become a journalist.

In Poland, at the time of Barbara's adolescence, it seemed obvious to get a university education, and also it was imperative to have a master's degree to study journalism. Barbara chose to study psychology, but before she graduated she realized that being a journalist in a communist country was a bit more complicated than expected. Therefore, when she got a PhD offer from two professors after her master's, she accepted. Since there were many candidates in social psychology, the professors decided on her behalf that she would become a doctoral student in industrial psychology. Barbara defended her dissertation in economics and psychology in 1976 at the Warsaw School of Economics and subsequently she worked at the Faculty of Psychology.

In 1981, Barbara got a Fellowship from American Council of Learned Societies (ACLS) at MIT Sloan School of Management. Shortly afterwards, however, martial law was imposed in Poland, which meant that she was not allowed to stay in the States. Barbara wanted to do field studies and she therefore went to Berlin, which two years after became a platform for moving to Stockholm's School of Economics as a visiting scholar, where she stayed until 1990. Then, after five years in Lund, she came to Gothenburg, which is now the place where she has lived and worked for the longest period in her life. The history of moving and the focus on field studies seem to be a red thread in Barbara's life, and hence her research. She has physically been moving from one place to another, and, theoretically, she has been jumping back and forth from one discipline to another, namely psychology, economics, management and literature. This multi-movement also relates to her approach to the field - for example, Barbara has both focused on doing field studies but also on how to do field studies, approaching field study methodology as a field in itself.

Barbara's dynamic attitude is reflected in her perception of her academic work life. She stresses that she has experienced the necessary conditions to pursue the things she found interesting and that she is good at. Summing up, the most thrilling thing about being in academia is, in her opinion: irregularities. 